\title{
Uso do Bagaço de Mandioca em Substituição ao Milho no Concentrado para Bovinos em Crescimento. 1. Consumo de Matéria Seca, Matéria Orgânica e Proteína Bruta ${ }^{1}$ \\ Paulo Roberto Ramos ${ }^{2}$, Ênio Rosa Prates ${ }^{3}$, Roberto Serena Fontanelli ${ }^{4}$, Júlio Otávio Jardim Barcellos $^{5}$, Itamar Bressan Bonelli ${ }^{6}$
}

\begin{abstract}
RESUMO - O objetivo deste trabalho foi avaliar o efeito da substituição do milho por bagaço de mandioca, no concentrado das rações, sobre o consumo de matéria seca (MS), matéria orgânica (MO) e proteína bruta (PB) de bovinos em crescimento. Dezesseis bezerros mestiços machos inteiros foram distribuídos em delineamento em blocos casualizados completos, em dois períodos. Quatro tipos de concentrado foram testados em associação com o fornecimento à vontade de feno de aveia/azevém (Avena strigosa, L.; Lolium multiflorum, L.) e suplementação média de concentrado de $0,83 \%$ PV. Os concentrados fornecidos aos animais diferenciaram-se pelo nível de substituição do milho por bagaço de mandioca: $\mathrm{T} 1=0,0, \mathrm{~T} 2=33,0, \mathrm{~T} 3=66,0$ e $\mathrm{T} 4=99,0 \%$. A substituição do milho por bagaço de mandioca no concentrado apresentou relação quadrática com o consumo de MS, MO e PB. O consumo máximo de MS, MO e PB foi, respectivamente, 88,$53 ; 82,34 ;$ e $10,61 \mathrm{~g} / \mathrm{kg}^{0,75}$. Os níveis de substituição de milho por bagaço de mandioca que geraram os consumos máximos foram 48,74; 44,14; e 43,75\%, respectivamente, para MS, MO e PB. Níveis mais altos de substituição do milho por bagaço de mandioca no concentrado reduziram o consumo dos componentes estudados.
\end{abstract}

Palavras-chave: bagaço de mandioca, bovinos, consumo, milho, subproduto, suplementação

\section{Use of Cassava Bagasse in Substitution of Corn in Concentrate for Growing Cattle. 1. Dry Matter, Organic Matter and Crude Protein Intake}

\begin{abstract}
The objective of this study was to evaluate the effect of the substitution of corn by cassava bagasse in the concentrate on dry matter, organic matter and crude protein intake in growing cattle. Sixteen crossbred bulls were allotted to a completely randomized block design, in two periods. Four types of concentrate were tested in association with an ad libitum allowance of oat/ryegrass hay (Avena strigosa, L.; Lolium multiflorum, L.) and an average concentrate supplementation of .83\% LW. The concentrates fed to the animals were different of corn by cassava bagasse by the substitution levels of corn: $\mathrm{T} 1=0.0, \mathrm{~T} 2=33.0$, $\mathrm{T} 3=66.0$, and $\mathrm{T} .04=99 \%$. There was a quadratic relation on DM, OM and CP intake. The maximum DM, OM and CP intake was, respectively, $88.53,82.34$, and $10.61 \mathrm{~g} / \mathrm{kg} \cdot{ }^{75}$. The corn by cassava bagasse substitution levels which produced the maximum intakes were: $48.74,44.14$, and $43.75 \%$, respectively, for DM, OM, and CP. Higher corn by cassava bagasse substitution levels in the concentrate reduced the intake of the components studied.
\end{abstract}

Key Words: cassava bagasse, cattle, intake, corn, by-product, supplementation

\section{Introdução}

Bovinos em crescimento apresentam alta exigência de nutrientes que, geralmente, não são encontrados, em níveis adequados, em dietas constituídas só por volumosos. Por isso, é necessária a suplementação com concentrados que, normalmente, têm preço elevado, aumentando o custo de produção. Um dos principais alimentos utilizados na formulação de concentrados é o milho. Porém, apesar de sua boa qualidade, muitas pesquisas são realizadas com o objetivo de estudar alternativas para sua substituição em dietas para bovinos. Os ruminantes que consomem milho concorrem com aves e suínos, que necessitam mais desta fonte de alimento, por não possuírem a mesma capacidade de aproveitamento das fibras que os ruminantes (MELLO et al., 1981). Além de grãos de cereais, vários subprodutos, como farelo de arroz,

\footnotetext{
1 Parte da dissertação de Mestrado do primeiro autor apresentada à UFRGS. Financiada em parte pelo CNPq.

2 M.Sc., Pesquisador da EPAGRI, Estação Experimental de Lages, Cx. Postal 181 - 88502-970 - Lages, SC. E-mail: ramos@epagri.rct-sc.br

3 Professor do Curso de Pós-graduação em Zootecnia, Faculdade de Agronomia da UFRGS, Cx. Postal 776 - $91001-970$, Porto Alegre, RS. E-mail: erprates@orion.ufrgs.br - Bolsista do CNPq.

4 Engo. Agro., M.Sc., Faculdade de Agronomia da UPF. Passo Fundo, RS.

5 Professor Assistente, M.Sc., Depto. de Zootecnia da UFRGS. Porto Alegre, RS.

${ }^{6}$ Engo . Agro., M.Sc., EPAGRI - Administração regional de Tubarão, Tubarão, SC.
} 
farelo de trigo e raspa de mandioca, são utilizados com relativo sucesso, constituindo o concentrado, diminuindo o uso do milho na sua composição. A raspa da mandioca é apontada por alguns autores (FERREIRA et al., 1989; FICHTNER et al., 1990) como bom substituto do milho. Porém, o processamento da mandioca para a produção de fécula gera ainda vários subprodutos, como o bagaço de mandioca, que tem sido fornecido com resultados satisfatórios para bovinos por alguns criadores (SILVEIRA, 1995). O bagaço de mandioca pode representar entre 10 e $20 \%$ do peso das raízes de mandioca utilizadas para a produção do amido, sendo que o mesmo pode conter até $60 \%$ de amido (BUTRIAGO, 1990).

Foi objetivo desta pesquisa estudar o efeito da substituição do milho pelo bagaço de mandioca no concentrado para bovinos recebendo volumoso de baixa qualidade.

\section{Material e Métodos}

O experimento foi conduzido nas instalações do Laboratório de Ensino Zootécnico, do Departamento de Zootecnia da Faculdade de Agronomia da UFRGS. Foram utilizados dezesseis novilhos machos inteiros, cruzas taurino x zebuíno, sem grau de sangue definido, com idade média de onze meses e peso médio inicial de $215 \mathrm{~kg}( \pm 31 \mathrm{~kg})$, mantidos confinados em baias individuais. O experimento constou, em média, de dois períodos de 28 dias. Os animais receberam alimento concentrado com média de $23,75 \%$ de proteína bruta (PB), sendo este composto de milho, bagaço de mandioca, farelo de soja, sal, calcário e uréia (Tabela 1). A oferta média diária de concentrado foi de $0,83 \%$ do peso vivo. Também foram fornecidos aos animais feno de aveia/azevém (Avena strigosa, L.; Lolium multiflorum, L.) (6,44\% PB) e água à vontade. O delineamento experimental foi o de blocos completos casualizados, sendo os dados submetidos às análises de covariância $(\mathrm{P}<0,05)$ e regressão $(\mathrm{P}<0,01)$, conforme (PIMENTEL GOMES (1978). As covariáveis estudadas foram: peso inicial(PI), consumo de concentrado (média do período) em relação ao peso inicial (CONC. \%PI) e consumo de volumoso (obtido no primeiro dia de cada período experimental) em relação ao peso inicial (VOLUM.\%PI).

Foram estabelecidos quatro tratamentos, consistindo em quatro níveis de substituição do milho do concentrado por bagaço de mandioca:

$\mathrm{T} 1$ : Feno à vontade $+0 \%$ de substituição do milho por bagaço de mandioca no concentrado.

T2: Feno à vontade $+33 \%$ de substituição do milho por bagaço de mandioca no concentrado.

T3: Feno à vontade $+66 \%$ de substituição do milho por bagaço de mandioca no concentrado.

T4: Feno à vontade $+99 \%$ de substituição do milho por bagaço de mandioca no concentrado.

Os tratamentos foram atribuídos a quatro animais por período.

Os dados sobre a composição química dos concentrados, do feno e do bagaço de mandioca utiliza-

Tabela 1 - Composição percentual dos alimentos usados nos concentrados e teores de proteína bruta (PB) (\% MS) Table 1 - Percentage participation of the feeds used in the concentrates and levels of crude protein (CP) (\% DM)

\begin{tabular}{|c|c|c|c|c|c|c|c|c|}
\hline \multirow[b]{3}{*}{ Alimento } & \multicolumn{8}{|c|}{$\begin{array}{c}\text { Tratamento } \\
\text { Treatment }\end{array}$} \\
\hline & \multicolumn{2}{|c|}{$\mathrm{T} 1$} & \multicolumn{2}{|c|}{$\mathrm{T} 2$} & \multicolumn{2}{|c|}{$\mathrm{T} 3$} & \multicolumn{2}{|c|}{$\mathrm{T} 4$} \\
\hline & MS & PB & MS & $\mathrm{PB}$ & MS & PB & MS & PB \\
\hline Feed & $D M$ & $C P$ & $D M$ & $C P$ & $D M$ & $C P$ & $D M$ & $C P$ \\
\hline Milho & 58,00 & 4,64 & 38,86 & 3,11 & 19,47 & 1,56 & 0,58 & 0,05 \\
\hline Corn & & & & & & & & \\
\hline $\begin{array}{l}\text { Bagaço de mandioca } \\
\text { Cassava bagasse }\end{array}$ & - & - & 19,14 & 0,41 & 38,94 & 0,90 & 57,42 & 1,32 \\
\hline $\begin{array}{l}\text { Farelo de soja } \\
\text { Soybean meal }\end{array}$ & 38,20 & 19,10 & 37,70 & 18,85 & 36,70 & 18,35 & 36,72 & 18,36 \\
\hline $\begin{array}{l}\text { Calcário } \\
\text { Limestone }\end{array}$ & 2,80 & - & 2,80 & - & 2,80 & - & 2,80 & - \\
\hline $\begin{array}{l}\text { Sal } \\
\text { Salt }\end{array}$ & 1,00 & - & 1,00 & - & 1,00 & - & 1,0 & - \\
\hline $\begin{array}{l}\text { Uréia } \\
\text { Urea }\end{array}$ & - & - & 0,50 & 1,36 & 1,09 & 2,94 & 1,48 & 4,01 \\
\hline Total & 100 & 23,74 & 100 & 23,73 & 100 & 23,75 & 100 & 23,74 \\
\hline
\end{tabular}


Rev. bras. zootec.

dos são apresentados na Tabela 2, especificados por tratamento e referentes à média dos dois períodos experimentais.

O feno fornecido aos animais foi picado, resultando em um material com tamanho predominante de partículas de cinco a nove centímetros.

O bagaço de mandioca utilizado no experimento foi armazenado em um silo de superfície revestido com lona plástica, sendo retirada deste uma fatia diária para o fornecimento aos animais.

A alimentação foi realizada em duas refeições diárias, às $8 \mathrm{~h} 30$ e $16 \mathrm{~h} 30 \mathrm{~h}$, sendo que o bagaço de mandioca foi misturado com o concentrado seco a cada refeição e fornecido aos animais 30 minutos antes da administração do feno.

\section{Resultados e Discussão}

O consumo médio diário de MS, MO e PB apresentou relação quadrática com a inclusão do bagaço de mandioca em substituição ao milho no concentrado (Tabela 3 e Figuras 1 e 2). Considerando-se o consumo em relação ao peso metabólico, as equações de regressão encontradas foram as seguintes:

MS: $\hat{\mathrm{Y}} 1=83,5456+0,2047 \mathrm{x}-0,0021 \mathrm{x}^{2} \quad(\mathrm{P}<0,01$ e $\left.\mathrm{r}^{2}=0,99\right) \quad \hat{\mathrm{Y}}$

MO: $\hat{Y} 2=78,8382+0,1589 \mathrm{x}-0,0018 \mathrm{x}^{2} \quad(\mathrm{P}<0,01$ e $\left.\mathrm{r}^{2}=0,98\right)$

PB: $\hat{Y} 3=10,3014+0,014 x-0,00016 x^{2}(P<0,01$ e $\mathrm{r}^{2}=0,98$ )

em que

Equação 1: $\hat{Y} 1$ = Consumo de MS em g/kg $/ 0,75 /$ dia; Equação 2: $\hat{Y} 2=$ Consumo de $\mathrm{MO}$ em g/ $/ \mathrm{kg}^{0,75} / / \mathrm{dia}$; Equação 3: $\hat{Y} 3$ = Consumo de $\mathrm{PB}$ em g/kg 0 ,75//dia; e $\mathrm{x}=$ Nível de substituição do milho por bagaço de mandioca $(\%)$.

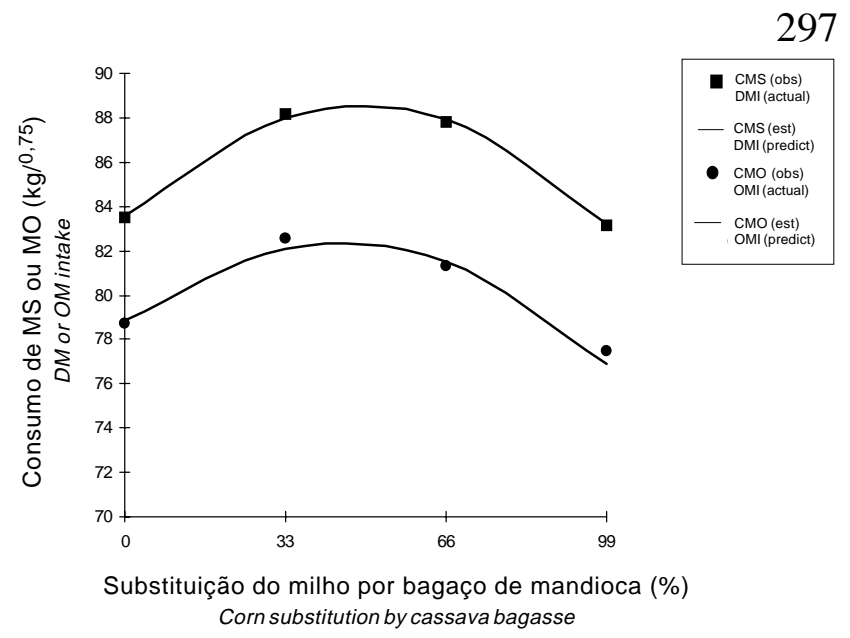

Figura 1 - Consumos totais de matéria seca (CMS) e matéria orgânica $(\mathrm{CMO})$ em relação aos níveis de substituição do milho pelo bagaço de mandioca no concentrado.

Figure 1 - Total dry matter (DMI) and organic matter intakes $(\mathrm{OMI})$ on the corn substitution levels by cassava in the concentrate.

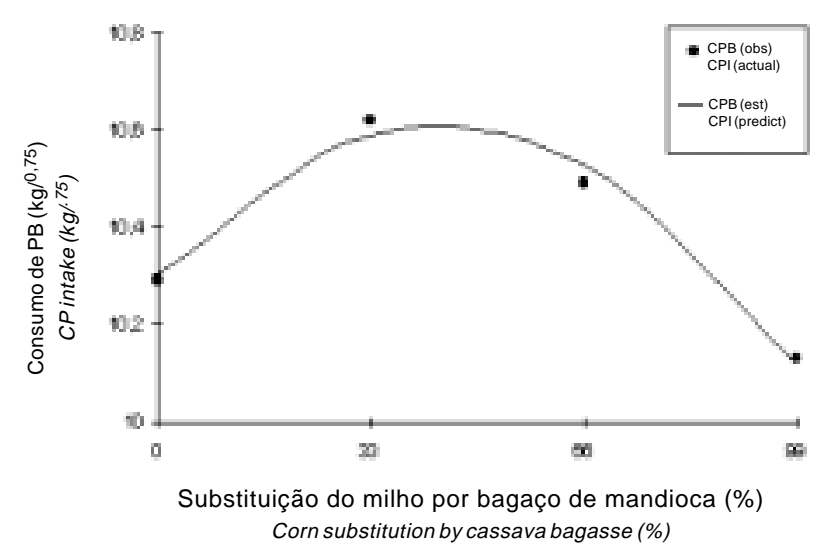

Figura 2 - Consumo de proteína bruta (CPB) em relação aos níveis de substituição de milho por bagaço de mandioca no concentrado.

Figure 2 - Crude protein intake (CPI) on the corn substitution levels by casssava bagasse in the concentrate.

Tabela 2 - Composição química dos alimentos usados na dieta. Média dos dois períodos (\% MS)

Table 2 - Chemical composition of the feeds used in the diet. Mean of the two periods (\% DM)

\begin{tabular}{|c|c|c|c|c|c|c|}
\hline \multirow[t]{2}{*}{ Item } & \multirow[t]{2}{*}{$\begin{array}{c}\text { Feno } \\
\text { Hay }\end{array}$} & \multicolumn{4}{|c|}{$\begin{array}{c}\text { Concentrado }^{1} \\
\text { Concentrate }\end{array}$} & \multirow[t]{2}{*}{$\begin{array}{c}\text { Bagaço de mandioca } \\
\text { Cassava bagasse }\end{array}$} \\
\hline & & $\mathrm{T} 1$ & $\mathrm{~T} 2$ & $\mathrm{~T} 3$ & $\mathrm{~T} 4$ & \\
\hline$\overline{\mathrm{MS}(D M)}$ & 87,97 & 88,11 & 88,52 & 89,30 & 89,45 & 17,23 \\
\hline $\mathrm{MO}(O M)$ & 93,45 & 93,05 & 91,23 & 88,52 & 85,28 & 95,74 \\
\hline $\mathrm{PB}(C P)$ & 6,44 & 24,26 & 28,31 & 34,50 & 44,58 & 2,30 \\
\hline $\mathrm{FDN}(N D F)$ & 76,24 & 23,78 & 24,64 & 22,81 & 27,89 & 34,90 \\
\hline $\operatorname{FDA}(A D F)$ & 49,40 & 7,10 & 8,25 & 10,11 & 8,54 & 29,36 \\
\hline Lignina & 5,52 & 3,90 & 1,16 & 3,52 & 1,80 & 5,93 \\
\hline Lignin & & & & & & \\
\hline $\begin{array}{l}\text { EB Mcal/kg } \\
\text { GE Mcal/kg }\end{array}$ & 4,36 & 4,28 & 4,34 & 4,53 & 4,47 & 4,21 \\
\hline
\end{tabular}

${ }^{1}$ Concentrado sem a adição de bagaço de mandioca.

Concentrate without cassava bagasse. 
298

Tabela 3 - Valores médios dos consumos diários de matéria seca (MS), matéria orgânica (MO) e proteína bruta (PB) por tratamento

Table 3 - Means of the daily dry matter (DM), organic matter $(O M)$ and crude protein $(C P)$ intakes

\begin{tabular}{lccc}
\hline $\begin{array}{l}\text { Tratamento } \\
\text { Treatment }\end{array}$ & \multicolumn{3}{c}{$\begin{array}{c}\text { Consumo } \\
\text { Intake }\end{array}$} \\
\cline { 2 - 4 } & MS & MO & PB \\
& OM & OM & $C P$ \\
\hline T1 & $-----------------g / \mathrm{kg}^{0,75}$ & 78,72 & 10,29 \\
T2 & 83,51 & 82,54 & 10,62 \\
T3 & 88,16 & 81,33 & 10,49 \\
T4 & 87,83 & 77,52 & 10,13 \\
DP $(S D)$ & 83,17 & 3,67 & 0,76 \\
CV \% & 4,10 & 4,58 & 7,33 \\
\hline DP & 4,78 &
\end{tabular}

DP (Desvio-padrão).

CV (Coeficiente de variação).

$S D$ (Standard deviation).

CV (Coefficient of variation).

Observou-se, pelos valores estimados pela equação 1, que até o nível de $48,74 \%$ de substituição do milho por bagaço de mandioca houve aumento no consumo de MS, alcançando máximo de $88,53 \mathrm{~kg} / 0,75 / \mathrm{dia}$, sendo que o consumo de MS diminuiu para níveis mais altos de inclusão do bagaço. Para o consumo de $\mathrm{MO}$ e $\mathrm{PB}$, os resultados foram semelhantes aos obtidos para o consumo de MS, sendo que o máximo consumo de MO $\left(82,34 \mathrm{~g} / \mathrm{kg} /{ }^{0,75}\right)$, estimado pela equação 2 , foi observado para $44,14 \%$ de substituição do milho, e o máximo consumo de PB $(10,61 \mathrm{~g} / \mathrm{kg} / 0,75)$, estimado pela equação 3 , foi verificado para $43,75 \%$ de substituição do milho, ambos diminuindo com o aumento subseqüente dos níveis de substituição (Figuras 1 e 2).

$\mathrm{O}$ aumento do consumo de MS de feno foi o responsável pelo aumento dos consumos de MS total, MO total e PB da dieta, uma vez que a quantidade de concentrado fornecida e o seu teor de PB foram os mesmos para todos os tratamentos e o feno foi fornecido à vontade, sendo que o seu consumo foi influenciado pelos tratamentos.

O maior consumo de MS até determinados níveis pode ter sido influenciado pela maior ou mais rápida degradação ruminal do amido proveniente do bagaço de mandioca.

Segundo HERRERA-SALDANA et al. (1990), o amido de milho é relativamente resistente à degradação no rúmen. ORSKOV et al. (1969) relataram que quantidades consideráveis de amido da dieta podem escapar da digestão no rúmen, quando são fornecidas aos animais dietas ricas em milho quebrado ou moído. ORSKOV (1986) registrou que $30 \%$ ou mais do amido de milho podem escapar da fermentação ruminal.
Entretanto, STUMPF (1992) obteve digestibilidade praticamente total do amido $(98,38 \%)$, em dietas em que se incluiu mandioca como suplemento. Esse autor observou desaparecimento médio da MS de mandioca de $66,64 \%$, após seis horas de incubação no rúmen, e de 91,64\%, após 12 horas, sendo que a degradabilidade potencial da MS de mandioca variou de 92,82 a $95,83 \%$.

Como o consumo de PB acompanhou o consumo de MS, é possível que a amônia proveniente da uréia, nos tratamentos T2, T3 e T4, tenha sido prontamente utilizada pelos microrganismos do rúmen na fermentação ruminal, possibilitando, assim, maior sincronismo entre a liberação de amônia e a fermentação dos carboidratos e, dessa forma, digestão mais rápida, permitindo maior consumo de MS da dieta. O fornecimento de níveis crescentes de carboidratos facilmente fermentáveis possibilita melhor utilização da uréia, devido à maior eficiência da utilização da amônia para a síntese de proteína microbiana (McLAREN et al., 1965; BELASCO, 1956). Este mecanismo pode ter atuado até certo nível, no qual o consumo de fibra em detergente ácido (FDA) não foi limitante.

O consumo de FDA aumentou linearmente com a substituição do milho por bagaço de mandioca, sendo que a equação de regressão encontrada foi: Consumo de FDA $=1,8289+0,00458 x\left(\mathrm{P}<0,01\right.$ e r $\left.{ }^{2}=0,86\right)$. A partir do nível de aproximadamente $50 \%$ de substituição de milho por bagaço de mandioca, o consumo de MS começou a diminuir em função do aumento do consumo de carboidratos estruturais da dieta, provocado pelo acréscimo do consumo de MS de feno. Isto acarretou redução da proporção de carboidratos prontamente fermentáveis da dieta, diminuindo a velocidade de fermentação dos carboidratos pelo aumento do consumo de carboidratos estruturais.

\section{Conclusões}

Para bovinos, a substituição do milho do concentrado por bagaço de mandioca, em níveis acima de $45 \%$, reduziu o consumo de matéria seca, matéria orgânica e proteína bruta.

O efeito positivo do aumento do consumo de MS da dieta, obtido com a utilização do bagaço de mandioca em substituição ao milho, foi limitado pelo maior consumo de carboidratos estruturais da dieta basal constituída por volumoso de baixa qualidade.

Devem ser recomendadas novas pesquisas avaliando a utilização do bagaço de mandioca em substituição ao milho, visando aumento do consumo de MS, mas tendo como componente da dieta basal um volumoso de melhor qualidade. 


\section{Referências Bibliográficas}

BELASCO, I.J. 1956. The role of carbohydrates in urea utilization, cellulose digestion and fatty acid formation. J. Anim. Sci., 15(2):496-508

BUTRIAGO, J.A.A. 1990. La yuca en la alimentation animal. Cali: Centro Internacional de Agricultura Tropical (CIAT). 446p.

FERREIRA, J.J., NETO, J.M., MIRANDA, E.S. de. 1989. Efeito do milho, sorgo e raspa de mandioca na ração sobre o desempenho de novilhos confinados. R. Soc. Bras. Zootec., 18(3):306-313.

FICHTNER, S.S., JARDIM, E.C., LOPES, H.O.S. et al. Uso de raspas de mandioca para bezerros. In: REUNIÃO ANUAL DA SOCIEDADE BRASILEIRA DE ZOOTECNIA, 27, 1990. Campinas. Anais ... Campinas: SBZ, 1990.p.38.

HERRERA-SALDANA, R. E., HUBER, J.T., POORE, M.H. 1990. Drymatter, crude protein, and starch degradability of five cereal grains. J. Dairy Sci., 73(9):2386-2393.

McLAREN, G. A., ANDERSON, G. C., TSAI, L.I. et al. 1965. Level of readily fermentable carbohydrate and adaptation of lambs to all-urea supplement rations. J. Nut., 87(3):331-336.

MELLO, R.P., MOREIRA, H. A., COELHO DA SILVA, J.F. 1981. Milho, sorgo ou mandioca dessecada comofontes energéticas em misturas iniciais para bezerros de rebanhos leiteiros. $R$. Soc. Bras. Zootec., 10(4):612-630.
ORSKOV, E.R. 1986. Starch digestion and utilization in ruminants. J. Anim. Sci., 63(6):1624-1633.

ORSKOV, E. R., FRASER, C., KAY, R. N.B. 1969. Dietary factors influencing the digestion of starch in the rumen and small and large intestine of early weaned lambs. Brit. J. Nutr., 23(1): 217-226.

PIMENTEL GOMES, F. 1978. Curso de Estatística Experimental, 8. ed., São Paulo: Nobel. 430p.

SILVEIRA, J.A. da. 1995. Tem resíduos virando carne. A Granja, Porto Alegre, 51(562):41-42.

STUMPF JR., W. Influência do amido do sorgo e da mandioca sobre a digestibilidade, parâmetros ruminais e plasmáticos em ovinos alimentados com feno. Porto Alegre: UFRGS, 1992. 343p. Tese (Doutorado em Zootecnia). Universidade Federal do Rio Grande do Sul, 1992.

Recebido em: 30/04/98

Aceito em: 16/12/98 